\title{
CALDERÓN Y LA 'MENTE CÓMICA' DE SUTIEMPO: EL EJEMPLO DE EL ASTRÓLOGO FINGIDO
}

\author{
Robert Folger \\ Ruprecht-Karls-Universität Heidelberg \\ Romanisches Seminar \\ Seminarstrasse 3 \\ 69117 Heidelberg \\ Alemania \\ robert.folger@rose.uni-heidelberg.de
}

\section{INTRODUCCIÓN}

En el año 2000 Anthony Close publicó una monografia con el título Cervantes and the Comic Mind of his Age ${ }^{1}$. En este estudio Close esencialmente intentó fundamentar la tesis de un trabajo anterior, The Romantic Approach to Don Quixote: A Critical History of the Romantic Tradition in Quixote Criticism del año 1978, en el cual había rechazado los acercamientos 'románticos' al Quijote, o sea, la imagen de Cervantes como creador olímpico e innovador radical, como genio exento tanto de las presiones ideológicas como de las ideas estéticas vigentes de su época ${ }^{2}$. Close se hacía eco de un artículo de P. E. Russell aparecido en 1969,

${ }^{1}$ En 2007, el estudio de Close se tradujo al español con el título Cervantes y la mentalidad cómica de su tiempo; mantengo el «mind» de Close porque obviamente lo quería distinguir de la «mentality» — término que se usa casi exclusivamente en el estudio- y porque 'mente' se asocia mejor con el concepto de la subjetividad que me interesa principalmente en este estudio.

${ }^{2}$ Ver El Saffar, 1979. 
según el cual hay que leer la pieza maestra de Cervantes como «funny book», como libro gracioso que fue ideado y recibido como vehículo de mero entretenimiento. The Comic Mind, fruto de más de veinte años de investigación, responde a las severas críticas por parte de los que creían en un sentido profundo del Quijote y que rechazaban la tesis historicista de Close, poniendo en tela de juicio la premisa de que el crítico moderno fuera capaz de reconstruir la recepción de la obra maestra de Cervantes por parte de sus contemporáneos ${ }^{3}$.

Por tanto Close emprendió la investigación comprensiva de una "mentalidad colectiva» que define como «inter-subjective thought: concepts, values, intuitive assumptions» ["pensamiento intersubjectivo: conceptos, valores, premisas intuitivas»] acerca de lo cómico ${ }^{4}$. De ahí que el trabajo del Close tenga una finalidad cervantista pero, al mismo tiempo, nos permita historizar las ideas, estéticas y funciones de lo cómico del Siglo de Oro hasta los años veinte del siglo XVII, cuando el joven Calderón emerge como autor de comedias. Creo que no es exagerado afirmar que la mayor contribución de Close no es necesariamente su interpretación del Quijote, porque es discutible hasta qué punto Cervantes es portavoz del mainstream de su época ${ }^{5}$. En cambio, su estudio puede resultar sumamente útil como punto de partida para el análisis de lo cómico en textos convencionales que reflejan, más o menos, las ideas y doctrinas vigentes en aquel tiempo. Los textos más convencionales o sea, estéticamente uniformes y conformes con las expectativas de las autoridades, tal vez sean las piezas teatrales porque, como espectáculos con un público harto representativo de la sociedad de la época, tenían que cumplir tanto con las expectativas estéticas (y cómicas) hegemónicas como con las normas oficiales.

Como nos recuerda Ignacio Arellano, los «recursos propiamente escénicos», «la prosémica, paralingüística, cinésica, vestuario, etc.» poseían una importancia fundamental en la comicidad del teatro calderoniano, y de la comedia en general ${ }^{6}$. Cabe preguntarse cuál es el principio o los principios unificadores de estos recursos teatrales y cómo se relacionaban con otras manifestaciones de lo cómico en la época. Aunque The

${ }^{3}$ La reseña de James Iffland (2001) proporciona una visión panorámica del debate que provocó el primer libro de Close.

${ }^{4}$ Close, 2000, p. 182. Todas las traducciones en el presente estudio son mías.

${ }^{5}$ Las objeciones de Iffland (2001) al respecto son válidas.

${ }^{6}$ Arellano, 1986, p. 48. 
Comic Mind de Close es en principio un análisis de lo cómico en los textos en prosa, el mismo autor justifica una ampliación de la perspectiva a la comedia porque afirma que Cervantes, a pesar de sus rivalidad con Lope, parte de la premisa de que «comedy — good, orthodox comedy - is the paradigm on which Don Quijote should be based» [«la comedia - la comedia buena y ortodoxa - es el paradigma en el que debe basarse el Don Quijote»]. Incluso afirma que: «Cervantes saw his fiction in the 'low' or comic mode primarily as an extension of comedy, the dramatic genre» [Cervantes veía su obra en el modo cómico 'bajo', fundamentalmente como extensión de la comedia, del género dramático»] ${ }^{8}$.

Seguidamente, voy a esbozar la mentalidad estudiada por Close y la evolución de esta mentalidad hasta comienzos del siglo XVII, usando este marco para determinar en qué medida El astrólogo fingido, una obra temprana de Calderón, y, por eso, pertinente a la dinámica descrita por Close, refleja la mentalidad colectiva, o sea, la 'mente cómica'. En un segundo apartado propongo ir más allá del rígido historicismo de Close, asociando El astrólogo fingido, y la comedia en general, con un concepto moderno de lo cómico, a saber el del francés Henri Bergson. La idea de la comicidad como reacción mecánica repetitiva y estereotipada a una experiencia vital, hace posible reflexionar no sólo sobre la estética de lo cómico en la comedia, y las ideas de la época sobre lo cómico, sino también sobre su función en una sociedad que tenía como fundamento ideológico la adherencia rígida y mecánica del individuo a códigos de conducta opresivos. Veremos cómo El astrólogo fingido es una obra particularmente apropiada para explorar el concepto de lo cómico en Calderón porque la figura del astrólogo es una metáfora de la metacomicidad esencial para el éxito y la fascinación de la comedia en general.

\section{LA MENTE CÓMICA}

Close abandona o, mejor dicho, matiza la perspectiva historicista radical que caracteriza a su The Romantic Approach en su estudio sobre la mente cómica. Describe la «mentalidad colectiva» de la mente cómica del tiempo de Cervantes como resultado de un proceso histórico, aná-

\footnotetext{
${ }^{7}$ Close, 2000, pp. 113-114.

${ }^{8}$ Close, 2000, pp. 113-114.
} 
logo al proceso de la civilización de Norbert Elias, la sociogénesis, o sea la paulatina represión de los deseos arcaicos y anárquicos del hombre y su sublimación en formas de refinamiento cultural y de la urbanidad ${ }^{9}$. Close asocia este proceso también con la emergencia de las sociedades disciplinarias tal como Michel Foucault ha postulado. Distingue, por tanto, dos etapas históricas en los Siglos de Oro que se caracterizan por dos 'mentalidades' relativas a lo cómico. Según Close, en el siglo XVI todavía predominaba el humor aristofánico, un humor rústico, físico, a menudo brutal, basado fundamentalmente en la noción de la «burla» violenta y caracterizado por la predilección por motes y apodos, a menudo insultantes. Todavía a comienzos del siglo XVI vemos este tipo de humor en obras como el Guzmán de Alfarache de Alemán y El Buscón de Quevedo, y, desde luego, el Quijote de Avellaneda, lo cual indica que Close no propone que una forma de lo cómico simplemente reemplazara a otra ${ }^{10}$, sino que se trababa de una 'domesticación' del humor más arcaico dentro de un nuevo marco. El estudioso norteamericano postula tres factores socio-culturales que producían este cambio:

$[T]$ he emergence of a large urban middle-to-upper class, looking to the court as role-model and acting as a primary cultural consumer; the prescriptive and authoritarian spirit of the age, which sought to observe and control social practices over a wide area; its pervasive academic ethos ${ }^{11}$.

La emergencia de una amplia clase entre media y superior, que tomaba la corte como modelo de comportamiento, y que era el principal consumidor cultural; el espíritu prescriptivo y autoritario de la época, que intentaba vigilar y controlar las prácticas sociales; un etos académico ubicuo.

Cervantes rechazó, según Close, el tradicional humor burlesco o quería transformarlo según sus principios éticos y estéticos; el creador del Quijote tenía, dice Close, una concepción aristotélica de lo cómico, propagando un humor que no era burlesco sino refinado y urbano. Este tipo de humor se relaciona con la mimesis de lo feo; las burlas no deben causar daño a la persona a la que se ridiculiza, y se supone que el humor

${ }^{9}$ Ver Close, 2000, pp. 198-199.

${ }^{10}$ Es sugerente el postulado de Raymond Williams, 1977, pp. 121-128, según el cual en una época coinciden estructuras y discursos residuales, dominantes y emergentes.

${ }^{11}$ Close, 2000, p. 216.Voy discutir el problema de esta visión de una sociedad opresiva en el apartado siguiente. 
tiene un efecto terapéutico para el público. Se trata, pues, de la purgación de los afectos y de los humores ${ }^{12}$. Por ende, el principio central de lo cómico cervantino es el aptum, la correspondencia entre el nivel y el estilo retóricos, la situación, y el estatus del hablante, de sus interlocutores y del auditorio. El énfasis en el aptum o decorum implicaba que Cervantes rechazaba tanto el humor tipo slapstick, y las burlas en boga en el siglo Xvi como el didacticismo sin paliativos que Alemán practica en su Guzmán de Alfarache.

Close identifica dos fenómenos culturales principales en la sociogénesis de nuevas formas del humor a finales del siglo Xvi: los manuales de cortesía que seguían el patrón del Cortegiano de Castiglione (la obra más significativa española es El Galateo español de Gracián Dantisco $[1586])^{13}$, y la emergencia de un nuevo etos académico que influiría en un abanico de formas literarias entre 1610 y 1630. El exponente más importante del academismo de la época fue Alonso López Pinciano. En su Philosophia antigua poética (1596) leemos:

De las palabras unas son urbanas y discretas, que, sin perjuicio de nadie notable, dan materia de risa; y esta especie es tal que puede parecer delante de reyes. Las demás, que nacen de la dicacidad y murmuración y fealdad y torpeza de palabras son malas y ansí se guarde el cómico della en todo caso de acciones delante de reyes y príncipes grandes, los cuales aborrecen naturalmente a toda fealdad ${ }^{14}$.

El principio del aptum es de suma importancia para el Pinciano, como demuestra también su veredicto acerca de que la persona noble debe reírse raramente, y que la risa frecuente y alta caracteriza al 'vulgo'.

El mismo Calderón nos proporciona, en su El médico de su honra, un ejemplo emblemático de la distinción del Pinciano. Coquín, el mozo de don Gutierre representa el papel del bufón y gracioso que provoca la risa con su lenguaje insolente y sus burlas. Hace una apuesta con el rey don Pedro, el cruel o el justiciero, según la perspectiva ${ }^{15}$, el rey que nunca se ríe: si no logra hacer reír al rey éste le hará sacar las muelas. Esta

${ }^{12}$ En cuanto al modelo psicosomático (pneumo-humoral) de la época de Cervantes ver Folger, 2002, particularmente pp. 27-33 y 234-248, y Folger, 2012a.

13 Relativo a la relación entre los manuales de cortesía y la novela picaresca, manifestación principal de lo cómico en el Siglo de Oro, ver Folger, 2009, pp. 134-154.

${ }^{14}$ López Pinciano, Philosophia antigua poética, p. 44.

15 Ver Folger, 2005. 
apuesta imaginada por Calderón marca una división social con respecto al lugar de la risa en la sociedad del Siglo de Oro. El acto de la extracción de las muelas nunca se realiza en El médico de su honra; sin embargo, Estebanillo González nos cuenta en su Vida:

Agarréle con el gatillo una muela que me pareció la más abultada de todas las demás, y por hacer reír a sus Majestades a costa de llanto ajeno tiré con tanta fuerza que no sólo se la saqué, pero muy gran parte de la quijada con ella. Empezó el judío a dar voces a sus camaradas a emperrarse contra mí, sus Majestades a reírse, y el pueblo a regocijarse ${ }^{16}$.

Este ejemplo demuestra que, en 1646, fecha de la publicación de la Vida, el humor asociado a la suma brutalidad seguía vigente en la mentalidad colectiva, tanto en la perspectiva del 'pueblo' como la de las élites aristocráticas ${ }^{17}$. A condición de que la víctima fuese apropiada, en este caso un judío, el precepto aristotélico de la inocuidad de la burla no valía ${ }^{18}$. El humor que Estebanillo pone en escena es el humor de los poderosos frente a los marginados: demuestra, como Thomas Hobbes postula en su tratado De Homine, la superioridad del que ríe ${ }^{19}$. Sin embargo, el mundo de los reyes, de los nobles y de las clases medias con aspiraciones de ascenso social era, idealiter, un mundo de entretenimiento sutil, de juegos verbales, conceptistas. Si los nobles eran las víctimas los efectos debían ser temporales e inocuos, de acuerdo con el principio aristotélico.

La anatomía de la mentalidad colectiva llevada a cabo por Close, le sirve para dar relieve al arte de Cervantes y su intento de producir un texto cómico en prosa. No obstante, como ya indiqué, la 'mente cómica' del Siglo de Oro puede servir como piedra de toque para la comicidad

${ }^{16}$ González, 1990, vol. 2, p. 94.

${ }^{17}$ La ordalía del judío y la risa del Emperador son una muestra de la relación entre el poder soberano y la «nuda vida» en el sentido de Giorgio Agamben; ver Folger, 2012b.

${ }^{18}$ También la 'batalla' épico-cómica con el rebaño de ovejas (I, 10) le cuesta varias muelas a Don Quijote.

19 "[T] he passion of laughter is nothing else but sudden glory arising from some sudden conception of some eminency in ourselves, by comparison with the infirmity of others...", ["La pasión de la risa no es otra cosa que la gloria repentina que surge del entendimiento súbito de cierta eminencia en nosotros, en comparación con la debilidad de los otros»] (Hobbes, «Human Nature, or the Fundamental Elements of Policy», p. 46); según R.E. Erwin, 2001, también Hobbes enfatiza la importancia de la moderación en la risa. 
en el teatro de Pedro Calderón de la Barca, particularmente en la etapa temprana de su trabajo como dramaturgo.Voy a probar la tesis de Close en un análisis de El astrólogo fingido, antes de volver sobre la cuestión de la función y de la lógica de la comicidad en la comedia áurea.

\section{El aStRólOGO FINGIDO Y LA SOCIOGÉNESIS DE lo CÓMICO, SEgÚN ClOSE}

El astrólogo fingido se publicó por primera vez en la Parte veinte y cinco de comedias recopiladas de diferentes autores en Zaragoza en el año de 1632. Se trata de unas de las obras tempranas de Calderón compuesta, probablemente, ya en $1625^{20}$, o sea en proximidad con la «mentalidad colectiva» reconstruida por Close. Es una obra de una muy notable difusión internacional, siendo, después de La vida es sueño, la más adaptada pieza calderoniana $^{21}$. A pesar de la popularidad y del éxito de la comedia, la crítica sobre la obra es escueta ${ }^{22}$.

Una de las razones es que se trata de una típica comedia de capa y espada, situada en el mundo de los espectadores madrileños contemporáneos, con los típicos enredos amorosos entre protagonistas que pertenecen a la nobleza, con un final súbito que restablece el honor de todos. La aparente o presunta falta de profundidad filosófica de esta obra de entretenimiento contribuyó seguramente al relativo desinterés por parte de los críticos, aunque no faltaban quiénes - hay que mencionar los estudios pioneros de Max Oppenheimer, Jr.- que postulaban cierta trascendencia de la obra. Analizando las «burlas» en la comedia y la isotopía del verbo 'fingir' y de sus derivaciones, Oppenheimer reconoce una preocupación ubicua de los personajes sobre la realidad de lo que experimentan. Volveré sobre el tema ${ }^{23}$.

El astrólogo fingido es una comedia de enredos, con una trama amorosa principal y cuatro tramas amorosas secundarias. Don Juan está enamorado de doña María. Como ella no corresponde a sus deseos decide

${ }^{20}$ Ver la cuidadosa introducción de Fernando Rodríguez-Gallego, 2011. En cuanto a la fecha de composición ver Rodríguez-Gallego, 2011, p. 12.

${ }^{21}$ Rodríguez-Gallego, 2011, pp. 14-15.

${ }^{22}$ Rodríguez-Gallego, 2011, pp. 17-25. A la literatura especializada reseñada por Rodríguez-Gallego hay que añadir un estudio reciente de Roberto González Echevarría en el que propone «ver la obra de Calderón como una ruptura con las ideas recibidas sobre la cosmología y la mitología del Renacimiento» (González Echevarría, 2015, p. 141).

${ }^{23}$ Ver Oppenheimer, 1948. 
irse a Flandes para morir allí como héroe. En la escena de despedida doña María confiesa que ella también lo ama, y que ha ocultado su amor por no hacer peligrar su honor, persuadiendo a don Juan a quedarse en Madrid en casa de un amigo, don Carlos, sin que nadie lo sepa. La criada de Doña María, Beatriz es cómplice en esta intriga (o «burla», como dice Oppenheimer) ${ }^{24}$. La segunda trama secundaria se centra en don Diego, un caballero que también está enamorado de doña María. Ésta lo rechaza abiertamente. DoñaViolante, a su vez, está enamorada de don Juan, sin conocer el amor de éste por doña María. Don Juan engaña a doña Violante al decirle que ha salido para Zaragoza. Don Carlos está secretamente enamorado de doña Violante, creyendo que su amigo don Juan también la quiere.

El motor de la acción teatral es la traición de Beatriz, quien revela al criado de don Diego, Morón, la relación amorosa secreta entre su ama y don Juan. Morón informa a don Diego, éste a sus amigos, e incluso Don Antonio se entera de la burla. Finalmente, el frustrado don Diego declara ante doña María que él conoce el secreto ya público. Para proteger a Beatriz y asistido por Morón y un amigo, don Diego pretende ser un astrólogo cuyos conocimientos astrológicos le han permitido acertar la verdad. La intriga del astrólogo fingido genera una serie de burlas menores, como veremos. Mientras tanto doña María y don Juan pretenden que éste es un amigo del hermano del padre de doña María, don Leonardo. Doña María regala una joya a don Juan, diciéndole a su padre que la ha perdido. Don Leonardo decide acudir al gran astrólogo para encontrar la joya. Como Beatriz ha informado al criado de don Diego, Morón, de que don Juan tiene la joya, don Diego es capaz de revelar a don Leonardo la verdad, afirmando su posición como astrólogo famoso. Engaña a doña Violante al decirle que don Juan la quiere, y convence a don Carlos de que también doña Violante lo ama a él. Don Juan intenta convencer a don Leonardo de que él es un ladrón para proteger a su amada. Finalmente don Leonardo, enterado de los amores entre su hija y don Juan, los casa para proteger su honor. Todos los otros que han sido burlados acusan a don Diego de mentiroso y falso astrólogo. Fin de la comedia.

Si miramos la comedia desde la óptica de la 'mente cómica' de Close es obvio que Calderón observa concienzudamente el principio del aptum de lo cómico que es central en la poética cervantina. Los motes y

\footnotetext{
${ }^{24}$ Ver la sinopsis de Oppenheimer, 1948, pp. 241-245.
} 
apodos no tienen casi ninguna importancia en la obra y se reducen a observaciones puestas en boca del gracioso Morón. El «juvenile, robust, Aristophanic style of humour» ["estilo de humor aristofánico, juvenil y burdo» $]^{25}$, un humor fisico y grosero, aparece de forma muy recudida, 'domesticada'. Me refiero a una escena que está, significativamente, modelada sobre el famoso episodio del Clavileño en la segunda parte del Don Quijote (cap. 41-42) ${ }^{26}$. Otáñez, «escudero vejete» ${ }^{27}$ de la casa de don Leonardo acude al famoso astrólogo y mago don Diego para que le ayude en un viaje a su pueblo en las montañas donde quiere esconder la pequeña fortuna («algún dinerillo») ${ }^{28}$ que ha acumulado. Morón se declara dispuesto a realizar el hechizo para su amo. Persuade a Otáñez para que se tape los ojos y se siente en una mula mágica que es, en realidad, un banco de madera. En esta situación ridícula, el escudero presencia las escenas y los diálogos que llevan al desenlace de las varias tramas. La analogía con la burla que los duques le hacen a don Quijote es evidente. Cervantes cualifica esta burla como honesto entretenimiento porque la víctima es el ridículo don Quijote y los autores de la burla son sus superiores. Como don Quijote, el «vejete» Otáñez se caracteriza, debido a su edad y su apariencia bizarra, "con botas y espuelas, y galán» ${ }^{29}$, por una 'fealdad' física y por su avaricia, una fealdad moral ${ }^{30}$. Según la doctrina aristotélica es, como don Quijote, una víctima apropiada para una burla, también porque no sufre ningún daño físico serio.

Aparte de esta escena en la que lo burlesco aparece de forma domesticada, el humor y lo cómico en la obra se caracterizan por la urbanitas que debía ser en principio lo cómico según los académicos y autores como Cervantes. La 'urbanidad' está ya inherente en el género de la

${ }^{25}$ Close, 2000, p. 189.

${ }^{26}$ Mata Induráin, 2011.

27 Caracterización inicial de las personae dramatis, Calderón, El astrólogo fingido, p. 201. Cito según el texto relaborado por Calderón para la publicación en la Segunda parte (1632), correspondiente a la sigla QC de Fernández-Gallego, indicando la página y los versos de la edición.

${ }^{28}$ Calderón, El astrólogo fingido, p. 316, v. 2497.

${ }^{29}$ Calderón, El astrólogo fingido, p. 326 (acotación).

${ }^{30}$ Morón insinúa que el escudero es un converso, lo cual éste contraria: «Mentís, que no soy judío», Calderón, El astrólogo fingido, p. 319, v. 2537. El Estebanillo González demuestra las graves 'consecuencias cómicas' la descendencia judía implicaba; véase arriba. 
comedia de capa y espada, con su escenario y dramatis personae ${ }^{31}$. El entretenimiento se nutre esencialmente del juego verbal y del entrelazamiento ingenioso de varias tramas. Don Diego, el astrólogo, es el personaje que frustra los planes de los otros con sus burlas, complicando la red de intrigas, hasta, finalmente, convertirse en víctima de sus propias maniobras. Aparentemente lo cómico está relacionado con la suspensión o frustración temporal de las expectativas y de los deseos así como del funcionamiento de las reglas de la vida cotidiana, culminando en el re-establecimiento del orden en las bodas de los dos protagonistas doña María y don Juan. El interés por el fingimiento o la burla constatado por Oppenheimer en la obra no refleja, en mi opinión, preocupación epistemológica ${ }^{32}$, sino que está esencialmente relacionado con la tensión entre patrones de conducta previsibles y la contingencia de los acontecimientos.

¿Qué hacemos, pues, con el principio del Pinciano de que el noble se ría poco? ¿Significa que el espectador de esta clase contemplaba la representación con ecuanimidad, gozando del entretenimiento 'decente' y sofocando la risa? Creo más bien que el teatro, la comedia, era el lugar socialmente asignado para la risa con el fin de controlarla, proporcionando una oportunidad 'apta' para la risa. Con esto se plantea la cuestión de qué provocaba la risa, y cuál era su función en la sociedad y culturas áureas. Parece lícito ir más allá del marco historicista de Close quien propone explicar la 'mentalidad colectiva' esencialmente según las ideas vigentes en la época.

\section{La Risa y lo mecánico (SEgún Bergson) en los roles sociales}

Los estudios de José Antonio Maravall sobre la cultura y sociedad áureas han ejercido considerable influencia sobre críticos de la comedia en tiempos de Calderón - y se han criticado severamente ${ }^{33}$. La imagen

${ }^{31}$ La caracterización clásica es de Franciso Bances Candamo en su Theatro de los theatros; ver Rodríguez-Gallego, El astrólogo fingido, p. 13, y Arellano, 1988.

32 Recientemente González Echevarría argumenta que en El astrólogo fingido la «antigua cosmografia se presenta de manera jocosa» (La vida es sueño, p. 145), vislumbrándose el «vaciamiento de códigos como la mitología y la cosmografía tolemaica» ( $\mathrm{La}$ vida es sueño, p. 158).

${ }^{33}$ En un reciente número monográfico de la revista Bulletin of the Comediantes, se reevalúa críticamente la «herencia de José Antonio Marvall»; ver la introducción de 
evocada por Maravall de una cultura opresiva oficial al servicio de un presunto régimen absolutista en la que el teatro, como vehículo de propaganda, era uno de los instrumentos de la opresión, ni se corresponde con la realidad social ni con la realidad vivida por las mujeres y hombres de Siglo de $\mathrm{Oro}^{34}$. Su constructo de una sociedad monolítica que oprimía el naciente individualismo moderno pasa por alto que tanto las estructuras de poder como la cultura de la época se caracterizaban por una notable heterogeneidad, distintos modos de agencialidad, si no 'disidencia' de los individuos, incluyendo a los dramaturgos contemporáneos. Incluso si se acepta la premisa de que el teatro tenía una función propagandística, el modelo top-down de la imposición del poder se desentiende del hecho de que el sujeto no solamente cede a la opresión sino que debe aceptar las normas y prerrogativas por voluntad propia para garantizar el orden ${ }^{35}$. Sin embargo la herencia de Maravall es, según Jonathan Thacker, el haber entendido que

there is clearly a battle between the self (variously characterized by him as 'conciencia íntima' or 'personal', 'propia personalidad', 'ser íntimo', 'esencia individual', or 'yo interior') and the way that society (through the dominant hierarchical, patriarchal, imperialist ideology) expects one to behave 'dada su posición'. The 'ser' is the knowable construct for these characters, not the troubling, potentially chaotic interior world ${ }^{36}$.

[hay, claramente, un lucha entre el Yo (caracterizado, en varias ocasiones, como 'conciencia íntima' o 'personal', 'propia personalidad', 'ser íntimo', 'esencia individual', o 'yo interior) y la manera en que la sociedad (mediante la ideología jerárquica, patriarcal e imperialista) calcula el comportamiento del sujeto ‘dada su posición'. El 'ser' no es el potencialmente caótico mundo interior sino el reconocible constructo de estos papeles].

Laura R. Bass, 2013.

${ }^{34}$ Una de las más severas críticas de Maravall es la historiadora Ruth Mackay que acusa a Maravall de privilegiar fuentes literarias en detrimento de la evidencia histórica; ver Mackay, 2013.

${ }^{35}$ La burocracia española que se desarrolla rápidamente a partir de la segunda mitad del siglo xv es uno de los dispositivos que 'invitaba' a los sujetos de asumir su posición en el tejido social y una 'economía de mercedes' generalizada; ver Folger, 2011, pp. 1652.

36 Thacker, 2013, p. 155 (suprimo las indicaciones de página en la cita). 
No existía una 'superestructura' del poder que inculcaba las normas y valores de una población dócil e inerte y que tenía que suprimir una «propia personalidad» o «esencia individual» independiente del mundo exterior porque la interioridad era el producto de interiorizaciones de papeles sociales. Estas interiorizaciones de 'papeles oficiales' producían, sin embargo, una individualidad - potencialmente disidente- como resultado de la multiplicidad y heterogeneidad de estos papeles ${ }^{37}$. Por tanto, George Mariscal habla, con razón, de «sujetos contradictorios» ${ }^{38}$. Mutatis mutandis, la dicotomía entre ser íntimo y papel social de Mariscal es útil porque es posible postular una tensión entre la subjetividad individual y una sociedad que proponía papeles, que — aunque eran múltiples y, en realidad, potencialmente contradictorios- prescribían determinadas normas de conducta y comportamiento. Creo que la comicidad del teatro calderoniano como se manifiesta en El astrólogo fingido, está relacionada con la complejidad de los sujetos de la época y la uniformidad de papeles específicos proporcionados por el aparato burocrático y la cultura en general ${ }^{39}$.

Hemos visto cómo los manuales de cortesía y los dispositivos sociales y religioso-políticos no solamente influenciaban la mentalidad colectiva relativa a lo cómico sino que proveían generalmente normas de conducta rígidas para el individuo - aunque no lo determinaban enteramente. La rigidez en el comportamiento humano es un término clave en la teoría de lo cómico o de la risa. Me refiero a los influyentes

${ }^{37}$ En cuanto a la relación entre la burocracia y la novela picaresca ver Folger, 2009. Folger, 2011, p. 46, propone que la identificación ideológica con imágenes procedentes del aparato estatal (interpelaciones en el sentido de Louis Althusser) no equivale a una determinación del individuo porque la agencialidad reside en la negociación de «subject positions» ["posiciones del sujeto»] como resultado de múltiples interpelaciones.

38 También en su estudio sobre la génesis del sujeto moderno, Anthony Cascardi, 1992, enfatiza que el sujeto se sitúa en una red de discursos conflictivos. Según William Egginton, 2003, el teatro es de particular importancia para la formación de la subjetividad moderna («teatralidad», en su terminología) porque se basa fundamentalmente en las prácticas visuales de la época. Postula que el teatro funciona como 'pantalla' en la cual el sujeto se identifica con las figuras en el escenario y sus valores, reconciliando fantasías individuales e ideología. Hans Ulrich Gumbrecht, 1990, divisa una tensión entre la emergencia de la subjetividad como resultado de la crisis de horizontes colectivos, y explica, como Maravall, la extraordinaria literatura del Siglo de Oro como resultado de la tensión entre la subjetividad moderna y la 'restauración' agresiva de la ortodoxia en la Contrarreforma.

${ }^{39}$ Sobre la relación entre burocracia y la naciente subjetividad moderna ver Folger, 2009 y 2011. 
trabajos del filósofo francés Henri Bergson (1859-1941). Aunque varios de los postulados de Bergson podrían usarse para explicar el humor en el teatro áureo (por ejemplo, la colectividad de la risa, el distanciamiento entre espectador y la persona risible ${ }^{40}$; el vicio como objeto privilegiado de la risa etc.), quiero limitarme al núcleo de la teoría bergsoniana, que también tiene validez filosófica fuera del marco del vitalismo decimomonónico. «Nous voyons en elle, avant tout, quelque chose de vivant» [«Vemos en en ella [sc. la risa] sobre todo algo vivo»] ${ }^{41}$.

Bergson nos da dos ejemplos de lo cómico. Primero, un hombre que corre por la calle, da una traspié, y se cae; segundo, otro hombre que cumple sus tareas con una «regularidad matemática» («régularité mathématique») $)^{42}$, pero alguien le ha hecho una burla y ha manipulado los objetos que le rodean: cuando moja su pluma en el tintero quiere sentarse, pero la silla se derrumba y él se encuentra en el suelo.

Ce qu'il y a de risible dans un cas comme dans l'autre, c'est une certaine raideur de mécanique là où $l^{\prime}$ on voudrait trouver la souplesse attentive et la vivante flexibilité d'une personne.

[Lo que hay de risible en los dos casos es una cierta rigidez mecánica donde se esperaría la agilidad y la flexibilidad de una persona].

Según Bergson, lo cómico se produce siempre cuando el ser humano no reacciona como lo exigirían las circunstancias de la experiencia vital, sino que actúa con una «rigidez mecánica» (raideur méchanique). La estereotipización de papeles sociales y la repetición de acciones se asocian intrínsecamente con lo cómico.

Esta rigidez mecánica en el comportamiento del individuo caracterizaba los papeles sociales que producían las normas culturales. La expresión emblemática de esta rigidez es el famoso código de honor que implica la supresión de sentimientos subjetivos y la negación de la realidad en aras de las apariencias, así como de las formas modernas de subjetividad. Por tanto, el comportamiento honroso, según los pape-

${ }^{40}$ Bergson postula que «l'insensibilité [...] accompagne d'ordinaire le rire» (3, bastardilla de Bergson) [ «la falta de sensibilidad acompaña normalmente a la risa», y una «anesthésie momentanée du coeur» [«una anestesia temporal del corazón»], haciendo eco de las burlas al estilo de Estebanillo.

${ }^{41}$ Bergson, 1958, p. 1.

42 Bergson, 1958, p. 7. 
les descritos, exigía reacciones mecánicas, experimentadas subjetivamente como cómicas. No hay que confundir un código de comportamiento con la 'realidad histórica', como demuestra el ejemplo más extremo del honor, puesto en escena por Calderón en El médico de su honra ${ }^{43}$. El uxoricidio como ultima ratio para defender el honor era una excepción de la realidad cotidiana que tenía severas consecuencias legales para el asesino. La fascinación por el uxoricidio radica en que el teatro ofrece una resolución imaginaria a un conflicto real (entre los sexos), como suplemento de una experiencia real ${ }^{44}$. El comportamiento de Gutierre tiene todas las características de un comportamiento cómico bergsoniano: en una "anestesia temporal del corazón» ${ }^{45}$, reacciona como una máquina. Sería descabellado ver en Gutierre un modelo de conducta para los espectadores; sería igualmente absurdo negar la existencia de un código de honor que tenía que producir efectos cómicos en muchas situaciones diarias. La sociedad y cultura del Siglo de Oro no estaban sujetas a una represión férrea, aunque sí se caracterizaban por más severas y amplias normas de 'conducta mecánica' que las nuestras - y menos válvulas para la risa. Es difícil imaginarse que la tragedia de El médico de su honra provocara la risa en el público, y es dificil imaginarse que la risa se permitiera en cada instante de un comportamiento mecánico, característico, a fin de cuentas, sobre todo de las élites sociales. Si Freud tiene razón, y la risa es un mecanismo para aliviar las tensiones de procesos de represión ${ }^{46}$, se necesitaba otra institución que hiciera posible la risa frente a la mecanicidad de la vida cotidiana: el teatro de la comedia.

El papel particular de la rigidez mecánica para lo cómico en la comedia española, se revela sobre todo en la meta-comicidad de El astrólogo fingido ${ }^{47}$. Cuando Doña María confiesa su amor por Don Juan, Beatriz observa:

En tu amor y tu elección dos novedades me ofreces.

${ }^{43}$ En lo siguiente, ver Folger, 2015.

${ }^{44}$ Folger, 2015, p. 91.

45 Ver n. 39.

${ }^{46}$ Freud, 1999, p. 133, argumenta «daß der Lustgewinn dem erspartem Gefühlsaufwand entspreche» ["que la ganancia equivale a la reducción del esfuerzo emocional»], o sea, que resulta en un relajamiento temporal de las represiones.

47 También González Echevarría, 2014, p. 144, enfatiza la «ironía auto-reflexiva», tildando la metateatralidad de "giro genial». 


\begin{abstract}
¡Querer al de menos fama, hacienda y nobleza! Dama de comedias me pareces, que toda mi vida vi en ellas aborrecido el rico y favorecido el pobre, donde advertí su notable impropiedad, pues, si las comedias son una viva imitación que retrata la verdad de lo mismo que sucede, a un pobre verle estimar ¿cómo se puede imitar, si ya suceder no puede? ${ }^{48}$
\end{abstract}

En varias ocasiones los personajes reflexionan sobre la rigidez mecánica que los estereotipos del género dramático imponen a los personajes de comedia. Estos estereotipos representan explícitamente la experiencia de los personajes en la diégesis de la pieza teatral.

Vemos otro ejemplo en la figura de Morón, quien es consciente de que su comportamiento está condicionado por las leyes de la comedia de capa y espada.

Yo tras mi amo he de ir;

cuanto él amare amaré,

que un criado siempre fue

en la tabla del amor

contrapeso del señor.

Adiós ${ }^{49}$.

Cuando Beatriz parece negarse a revelar el secreto amoroso de su ama ("Jamás de mi boca lo sabrás»), Morón enfatiza el 'deber' y la lógica que implica el papel de criada de comedia para ella.

Pues de ti lo he de saber:

¿no sirves y eres mujer?

${ }^{48}$ Calderón, El astrólogo fingido, pp. 207-208, vv. 92-108.

${ }^{49}$ Calderón, El astrólogo fingido, p. 224, vv. 451-458. 
BeAtriz

Sí.

Pues tú me lo dirás ${ }^{50}$.

Ya que Beatriz es una criada, la lógica de las convenciones de la comedia y, por tanto, las expectativas tanto del público como de los otros personajes exigen que delate el secreto.

En los tres ejemplos queda claro que la comicidad del argumento se basa en las reacciones mecánicas de los personajes. La pieza calderoniana demuestra que en el teatro la comicidad experimentada pero parcialmente reprimida en la vida cotidiana encontraba su expresión, produciendo un alivio en los espectadores no solamente por la risa sino también por la identificación imaginaria con lo representado. La particularidad de El astrólogo fingido está en que articula un mecanismo fundamental que produce la comicidad en el teatro áureo: los espectadores adivinan el comportamiento de los personajes tanto como los personajes adivinan las acciones de los otros, según códigos convencionalizados del género, reflejando de manera cómica su conducta en la vida diaria. No olvidemos que el mundo evocado en la comedia de capa y espada es un simulacro idealizado de la vida en Madrid. En este sentido la figura del astrólogo fingido es una metáfora para la vida en el Siglo de Oro: finge, o representa un papel, y examina y calcula 'constelaciones' sociales como un astrólogo — resultando en situaciones cómicas.

Es obvio que el astrólogo es la figura identificatoria principal en la comedia porque refleja la experiencia cotidiana de enfrentarse a constelaciones sociales mecánicas. La risa que provoca la comedia calderoniana El astrólogo fingido, es la risa del espectador sobre su propio comportamiento reflejado en las acciones mecánicas de los personajes; es una forma de superar la ridiculez inherente de la vida cotidiana en el Siglo de Oro español.

${ }^{50}$ Calderón, El astrólogo fingido, p. 226, vv. 484-489. 


\section{BibLIOGRAFÍA}

Arellano, Ignacio, «La comicidad escénica en Calderón», Bulletin Hispanique, 88, 1-2, 1986, pp. 47-92.

Arellano, Ignacio, «Teoría dramática y práctica teatral sobre el teatro áulico y político de Bances Candamo», Criticón, 42, 1988, pp. 169-193.

Bass, Laura R., «The Comedia and Cultural Control: The Legacy of José Antonio Maravall», Bulletin of the Comediantes [Special Issue], 65, 1, 2013, pp. 1-13.

Bergson, Henri, Le rire: essai sur la signification du comique [1900], Paris, Presses Universitaires de France, 1958.

Calderón de la Barca, Pedro, El astrólogo fingido [1637], ed. Fernando Rodríguez-Gallego, Madrid / Frankfurt, Iberoamericana / Vervuert, 2011.

Cascardi, Anthony J., The Subject of Modernity, Cambridge, Cambridge University Press, 1992.

Close, Anthony, Cervantes and the Comic Mind of His Age, Oxford, Oxford University Press, 2000.

Close, Anthony, Cervantes y la mentalidad cómica de su tiempo, trad. Leticia Iglesias Pedronzo y Carlos Conde Solares, Alcalá de Henares, Centro de Estudios Cervantinos, 2007.

Close, Anthony, The Romantic Approach to Don Quixote, New York, Cambridge University Press, 1978.

Egginton, William, How the World Became a Stage: Presence, Theatricality and the Question of Modernity, Albany, NY, SUNY Press, 2003.

El Saffar, Ruth, "On Anthony Close's Cervantes and the Romantic Approach to Don Quixote», Modern Language Notes, 94, 1979, pp. 399-405.

Erwin, Robert E., «Hobbes on Laughter», Philosophical Quarterly, 51, 202, 200, pp. 29-40.

Folger, Robert, «Die Natur der Frau im Siglo de Oro: Juan Huarte de San Juan und María de Zayas», Begriff und Darstellung der Natur in der spanischen Literatur der Frühen Neuzeit, ed. Gerhard Poppenberg y Wolfgang Matzat, München, Wilhelm Fink, 2012a, pp. 183-203.

Folger, Robert, “"Tened... que no soy Ecce-Homo”: El Buscón, el inconsciente político y la nuda vida", en Narrar la pluralidad cultural: crisis de modernidad $y$ funciones de lo popular en la novela de lengua española, ed. Max Grosse y Wolfgang Matzat, Madrid / Frankfurt, Iberoamericana / Vervuert, 2012b, pp. 67-95.

Folger, Robert, «"Pedro... planeta soberano de Castilla": género literario y violencia absoluta en El médico de su honra», en Calderón frente a los géneros dramáticos, ed. Antonio Sánchez Jiménez, Madrid, Ediciones del Orto, 2015, pp. 83-102. 
Folger, Robert, Picaresque and Bureaucracy: «Lazarillo De Tormes», Newark, Delaware, Juan de la Cuesta, 2009.

Folger, Robert, Writing as Poaching: Interpellation and Self-Fashioning in Colonial "relaciones de méritos y servicios», Leiden / Boston, Brill, 2011.

Folger, Robert, Images in Mind: Lovesickness, Spanish Sentimental Fiction and "Don Quijote», Chapel Hill, University of North Carolina Press, 2002.

Freud, Sigmund, Der Witz und seine Beziehung zum Unbewußten [1905], Gesammelte Werke, Frankfurt, Fischer, 1999.

GonzÁLEZ, Estebanillo [?], La vida y hechos de Estebanillo González, hombre de buen humor, compuesto por el mesmo [1646], ed. Antonio Carreira y Jesús Antonio Cid, Madrid, Cátedra, 1990, 2 vols.

González Echevarría, Roberto, «Infinito e improvisación en La vida es sueño», Bulletin of the Comediantes, 66, 2, 2014, pp. 141-160.

Gumbrecht, Hans Ulrich, Eine Geschichte der spanischen Literatur, Frankfurt, Suhrkamp, 1990.

Hobbes, Thomas, "Human Nature, or the Fundamental Elements of Policy» [1658], The Collected Works of Thomas Hobbes, vol. IV, ed.William Molesworth, London, Routledge, Thoemmes Press, 1994, pp. 1-76.

IfFland, James, «Laughter Tamed», Cervantes: Bulletin of the Cervantes Society of America, 23, 2, 2003, pp. 395-435.

López Pinciano, Alonso, Philosophia antigua poética [1596], ed. Alfredo Carballo Picazo, vol. 3, Madrid, CSIC, 1953.

MacKay, Ruth, "The Maravall Problem: A Historical Inquiry», Bulletin of the Comediantes [Special Issue], 65, 1, 2013, pp. 45-56.

Mariscal, George, Contradictory Subjects: Quevedo, Cervantes, and SeventeenthCentury Spanish Culture, Ithaca, NY, Cornell University Press, 1991.

Mata Induráin, Carlos, "Cervantes y Calderón: El episodio de Clavileño (Quijote II, 40-41) y la burla a Otáñez en El astrólogo fingido», en Volver a Cervantes. Actas del IV Congreso Internacional de la Asociación de Cervantistas, ed. Antonio Bernat Vistarini, Palma de Mallorca, Universitat de les Illes Balears, 2001, vol. 2, pp. 999-1014.

Oppenheimer, Max, Jr., "The burla in Calderón's El astrólogo fingido», Philological Quarterly, 27, 1948, pp. 241-263.

Rodríguez-Gallego, Fernando, «Introducción», Pedro Calderón de la Barca, El astrólogo fingido, ed. Fernando Rodríguez-Gallego, Madrid / Frankfurt, Iberoamericana / Vervuert, 2011, pp. 11-199.

Russell, Peter E., "Don Quijote as a Funny Book», Modern Language Review, 64, 1969, pp. 312-326.

Thacker, Jonathan, «Maravall and the Self in the comedia nueva», Bulletin of the Comediantes [Special Issue], 65, 1, 2013, pp. 155-173.

Williams, Raymond, Marxism and Literature, Oxford, Oxford University Press, 1977. 